\title{
Reputations in the adoption of a new technology
}

\author{
Kenneth Hendricks* \\ University of British Columbia, Vancouver, B.C., Canada
}

Final version received July 1991

This paper studies the effects of uncertainty on the timing of adoption of a new technology in a duopoly. Firms are uncertain of the innovative capabilities of their rivals and about the profitability of adoption. These features lead to a richer and, in some respects, more plausible theory of adoption, in which rents from delayed adoption are always realized, and returns are not equalized across adoption times.

\section{Introduction}

In the past decade, an extensive literature has developed on the diffusion of new technologies. There are two main strands. The first is exemplified by the decision-theoretic models of Balcer and Lippman (1984), Bhattacharya, Chatterjee and Samuelson (1988), Jensen (1982, 1988), and McCardle (1985). These papers seek to explain why firms frequently delay adoption of new technologies and, in some cases, fail to adopt altogether. The explanations focus on uncertainty about the innovation process and the desire of firms to learn more about their returns before committing themselves to a new technology.

The second strand focuses on externalities in the diffusion process. Because adoption generally increases the profit flow of the adopter at the expense of its rivals, the decision by a firm of whether and when to adopt depends in part upon the adoption decisions of its rivals. Benoit (1985) and Reinganum (1983) examine how this interaction determines the likelihood of adoption in a duopoly model where returns are stochastic. The timing issue is the subject of a number of papers. Fudenberg and Tirole (1985), Gilbert and Harris (1984), Reinganum (1981a,b) study symmetric contests, and Eaton and Lipsey (1979) and Gilbert and Newberry (1982) study asymmetric contests

Correspondence to: K. Hendricks, Department of Economics, University of British Columbia, 997-1873 East Mall, Vancouver, B.C., Canada V6T 1W5.

*I am grateful to Curtis Eaton, Ken Judd, Robert Porter, Michael Riordan and two anonymous referees for helpful comments and suggestions. Financial support from the Hoover Institution and Social Science Research Council of Canada is gratefully acknowledged. 
between an incumbent firm and an entrant. Reinganum shows that, if firms can precommit to adoption times, they adopt at different times, and the firm which adopts earlier earns more rents than firms which adopt later. The other authors argue that the precommitment solution is not reasonable, since firms can observe adoption by a rival and will want to respond optimally to that event. The prediction of these models is that one of the firms adopts preemptively as soon as it is profitable for its rival to do so. Adoption is diffused, but rents from delayed adoption due to learning or growing demand or declining adoption costs are dissipated. The exception is the work of Fudenberg and Tirole who show that, if preemption gains are relatively small, then firms may be able to avoid the preemption outcome and adopt jointly at some later date.

The purpose of this paper is to show that, even if preemption gains are large, rent dissipation does not occur if firms have arbitrarily small doubts about each other's innovative capabilities. More precisely, I borrow from Benoit (1985) the idea that there are two types of firms: innovators and imitators. Each firm knows only its own type, so each cannot be sure that its rival wants to adopt first. Innovator types use these doubts as a basis for cooperation. They tacitly agree to delay adoption for a period of time, after which they develop reputations as imitators by randomizing. The qualitative features of the equilibrium are similar to those of the precommitment solution: a substantial fraction of the rents from delayed adoption are realized and the first adopter earns more than the second adopter.

This point takes on a particular significance in view of the experimental work by McKelvey and Palfrey (1991). They report on a scrics of expcriments in which individuals play a version of a game known as the centipede game. This game is essentially a discrete version of the adoption game considered in this paper. It possesses a unique equilibrium outcome in which the game ends with preemption at the first move. The experimental results were not consistent with this prediction. It occurred in only 37 of 662 games. However, the authors found that a model in which subjects believed that there is a small chance that their opponent is an altruist (i.e., a player who does not move first) explained the data very well.

The paper is organized as follows. In section 2, I introduce the duopoly model, which is essentially a parameterized version of the ReinganumFudenberg-Tirole (R-FT) model. In section 3, I characterize the equilibrium of the model when preemption gains are large and firms have doubts about the innovative capabilities of their rival. In section 4, I discuss the effects of uncertain profitability. Concluding remarks follow in section 5 .

\section{The model}

There are two firms in the industry, indexed by $i=1,2$. At time 0 , a new, 
cost reducing technology is announced. Each firm must choose when to adopt the new technology. The undiscounted cost of purchasing the new technology and bringing it on line hy time $t$ declines with time. The cost function is assumed to be the same for each firm and takes the form $c(t)=e^{-\alpha t}$, where $\alpha>0$ is the rate of decline parameter.

The profit flows arc dcfined as follows: $\pi_{0}(0)$ is the profit flow of each firm when both firms are using the old technology; $\pi_{0}(1)$ is the profit flow of firm $i$ when firm $j$ has adopted the new technology and firm $i$ has not; $\pi_{1}(1)$ is the profit flow of firm $i$ when it has adopted the new technology and firm $j$ has not; $\pi_{1}(2)$ is the profit flow of firm $i$ when both firms have adopted the new technology. Each firm discounts future revenues at rate $\delta$.

With some modifications, I adopt the Reinganum-Fudenberg-Tirole assumptions on profit flows. Assumption (A1) ranks the profit flows.

$$
0<\pi_{0}(1)<\pi_{0}(0)<\pi_{1}(2)<\pi_{1}(1) .
$$

All profit flows are positive. Adopting the new technology always increases the profit flow of the adopter and decreases the profit flow of the nonadopter. Finally, the new technology generates higher profit flows than the old technology even after both firms have adopted it. Hence, if adoption costs are low, both firms should adopt the technology at some point.

R FT also impose the following restriction:

(i) $\pi_{1}(1)-\pi_{0}(0)>\pi_{1}(2)-\pi_{0}(1)$;

(ii) $\pi_{1}(1)-\pi_{0}(0)<\delta+\alpha$.

Condition (i) states that the increase in profit rates due to adopting first exceed those of adopting second. Condition (ii) states that the increase in profit flow to the first adopter is less than the instantaneous gain from waiting at time 0 if adoption costs are low. Thus, if firm $i$ waits at time 0 , firm $j$ has no incentive to preempt.

A simple way of introducing uncertainty about a rival's willingness to adopt first into the R-FT model is to assume that each firm believes that there is some chance that its rival is not an innovator, but an imitator. An imitator type never adopts first. However, after the other firm has adopted, it has the same technological possibilities as that firm. Consequently, its behavior as a follower is the same as that of an innovator. The interpretation here is that an imitator does not possess the requisite physical and human capital to initiate adoption, but it can duplicate the efforts of a rival once that firm has adopted.

Following Fudenberg and Tirole, I assume that firms can observe their rival's actions and respond immediately if they so choose. Thus, neither firm 
can precommit to an adoption time, but must behave optimally at each instant of time given its type and the history of actions taken prior to that time. Note that the decision problem of each firm after its rival has adopted first is nonstrategic. Hence, it will be convenient to first solve for the optimal strategy of a follower. That is, suppose firm $j$ adopts at time $t$ and firm $i$ has not. Then firm $i$ will want to adopt at time $t$ if and only if the increase in profit flow is at least as great as the opportunity cost of adoption. Let $\hat{T}$ denote the earliest time at which this event occurs. It solves the equation,

$$
\pi_{1}(2)-\pi_{0}(1)=(\alpha+\delta) e^{-\alpha \hat{T}}
$$

It follows from Assumption (A2) that eq. (2.1) has a solution. The optimal response for each firm $i$ as a follower can then be expressed as follows:

$$
\begin{aligned}
& \tau(t)=t \text { if } t \geqq \hat{T}, \\
& \hat{T} \quad \text { otherwise. }
\end{aligned}
$$

Notice that $\tau(\cdot)$ is not indexed by type, since an imitator is assumed to behave in exactly the same way as an innovator when it is a follower.

In evaluating the profitability of adopting now rather than later, each firm anticipates its rival's optimal response. Hence, given (2.2), returns to adopting first at time $t$ for an innovator type are

$$
L(t)=\pi_{0}(0)\left(1-e^{-\delta t}\right) / \delta-e^{-(\delta+z) t}+\int_{t}^{\tau(t)} \pi_{1}(1) e^{-\delta s} \mathrm{~d} s+\int_{\tau(t)}^{\infty} \pi_{1}(2) e^{-\delta s} \mathrm{ds}
$$

Prior to adoption at time $t$, the innovator firm earns $\pi_{0}(0)$. At time $t$, it adopts first and incurs adoption costs equal to $e^{-\alpha t}$. It then earns $\pi_{1}(1)$ until time $\tau(t)$, after which its profit flow falls to $\pi_{1}(2)$ due to adoption by firm $j$. $\Lambda \mathrm{ll}$ cash flows are discounted back to time 0 .

If firm $j$ leads at time $t$, the returns to firm $i$ when it is an innovator are

$$
F(t)=\pi_{0}(0)\left(1-e^{-\delta t}\right) / \delta-e^{-(\delta+\alpha) \tau(t)}+\int_{t}^{\tau(t)} \pi_{0}(1) e^{-\delta s} \mathrm{~d} s+\int_{\tau(t)}^{\infty} \pi_{1}(2) e^{-\delta s} \mathrm{~d} s .
$$

It earns $\pi_{0}(0)$ prior to $t, \pi_{0}(1)$ until time $\tau(t)$, at which time it switches to the new technology at a cost equal to $e^{-\alpha \tau(t)}$, and earns $\pi_{1}(2)$ forever after.

Finally, if both firms adopt simultaneously at time $t$, the expected returns to each firm are 


$$
M(t)=\pi_{0}(0)\left(1-e^{-\delta t}\right) / \delta+e^{-\delta t} \pi_{1}(2) / \delta-e^{-(\delta+\alpha) t}
$$

I shall formalize the game using the normal form rather than the extensive form. A (pure) strategy for firm $i$ when it is an innovator is a map from $[0, \infty)$ to $\{0,1\}$, where 0 denotes 'wait' and 1 denotes 'adopt'. It specifies the action which firm $i$ intends to take at each instant of time if no firm as adopted previously. In the normal form, however, the only aspect of an innovator's strategy that matters is the earliest time at which it plans to adopt conditional on neither firm adopting prior to that time. Let $t^{i}$ denote this time for an innovator firm $i$. Its behavior at times after $t^{i}$ is not relevant, since it has no effect on its payoffs or those of firm $j$. Consequently, there is no loss of generality in referring to $t^{i}$ as the strategy of firm $i$ when it is an innovator. ${ }^{1}$ Letting $q$ denote each firm's belief that its rival is an innovator, the expected payoffs to firm $i$ as an innovator from the strategy pair $\left(t^{1}, t^{2}\right)$ is

$$
P^{i}\left(t^{i}, t^{j}\right)= \begin{cases}L\left(t^{i}\right) & \text { if } t^{i}<t^{j} \\ (1-q) M\left(t^{t}\right)+q L\left(t^{i}\right) & \text { if } t^{i}=t^{j} \\ (1-\mathrm{q}) \mathrm{F}\left(\mathrm{t}^{\mathrm{j}}\right)+\mathrm{qL}\left(\mathrm{t}^{\mathrm{i}}\right) & \text { if } t^{i}>t^{j} .\end{cases}
$$

In what follows, it will be important to permit innovator types to randomize. Since, in the normal form, the space of pure strategies for an innovator type can be defined as $\mathbb{R}_{+}$, a mixed strategy can be represented by a distribution function $G^{i 2} .^{2}$ If the domain of the payoff functions is extended to the set of all pairs of mixed strategies in the obvious way, then a strategy combination $\left(\hat{G}^{1}, \widehat{G}^{2}\right)$ is an equilibrium if $P^{i}\left(\widehat{G}^{i}, \widehat{G}^{j}\right) \geqq P^{i}\left(G^{i}, \widehat{G}^{j}\right)$ for all mixed strategies $G^{i}, i=1,2$ and $i \neq j$. For the remainder of the paper, $\left(G^{1}, G^{2}\right)$ will refer to an equilibrium combination, and $r^{i}(t)$ will denote the probability that firm $i$ adopts at exactly time $t$ when it is an innovator.

The main reason for using the normal form rather than the extensive forms is that mixcd stratcgics can be defined on $\mathbb{R}_{+}$, rather than on a function space. (See Fudenberg and Tirole, and also Bergin (1988), Simon and Stinchcombe (1989), Simon (1987) for a more technical discussion of the problems of formulating continuous time games such as the above in the extensive form.) However, one of the problems with the normal form is that it admits equilibria in which players make empty threats. This is the main motivation for using the extensive form and associated solution concepts. Fortunately, for the case at hand, the normal form is adequate. The reason is that the probability of reaching any time $t$ is at least $q^{2}$, which is positive.

\footnotetext{
${ }^{1}$ More precisely, $t^{i}$ is a pure strategy in the reduced normal form. This is obtained from the normal form by deleting duplicate strategies (i.e., those which yield the same payoffs).

${ }^{2}$ By a probability distribution, $I$ mean any right-continuous, nondecreasing function $G$ from $(-\infty, \infty]$ to $[0,1]$ with $G(t)=0$ for $t<0$ and $G(\infty)=1$. The probability of the event that a firm does not adopt is defined as $1-\lim _{t \rightarrow \infty} G(t)$.
} 


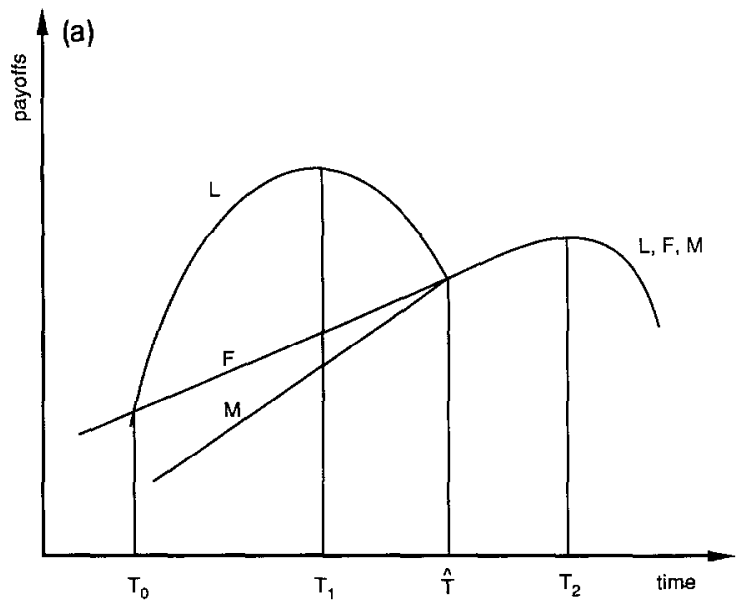

Fig. 1a.

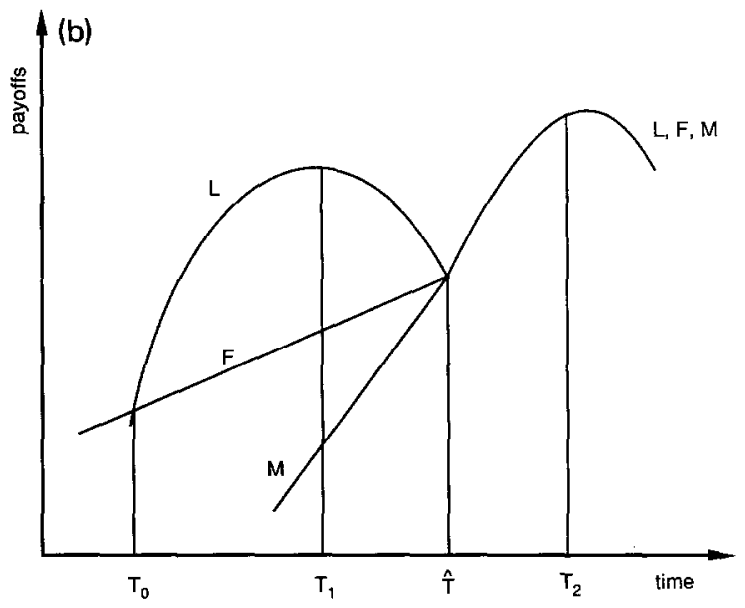

Fig. 1b.

Hence, each firm must anticipate having to play the action prescribed by its strategy for that time if it plans not to adopt before then. When this is the casc, Nash cquilibrium rulcs out incrcdible threats.

\section{Reputation building when preemption gains are large}

Fudenberg and Tirole have demonstrated that there are two possible configurations for the return functions given in the previous section. These are depicted in figs. $1 \mathrm{a}$ and $1 \mathrm{~b}$, which are adapted from their article. Recall that $\hat{T}$ is the first time that the optimal response to adoption by a rival is to 
adopt an instant later. Thus, $L, F$, and $M$ are identical after $\hat{T}$. They are increasing at $\hat{T}$ because the rate of decline in adoption costs exceeds the increase in net profit flow from switching to the new technology. After $T_{2}$, the benefits from switching are less than those from waiting. Hence, $T_{2}$ is a local maximum for the return functions.

Prior to $\widehat{T}$, both the returns to following and leading exceed those from tying. The former because the best response to adoption at $t$ is to wait until $\hat{T}$ to adopt instead of at $t$, and the latter because the returns to adopting first are an increasing function of the adoption time of the follower. Moreover, $F$ is increasing prior to $\hat{T}$ since the length of time during which the follower is at a cost disadvantage decreases with the adoption time of the leader. FT shows that the assumptions given above (in particular, A2(i)) imply that $L$ has a local maximum at $T_{1}$ and, at that time, preemption gains are positive. The intuition is that if a firm waits until later to lead, the period of cost advantage is shorter, and this can cause returns to leading to fall even though adoption costs are lower. Note that, since Assumption A2(ii) implies that $F(0)$ exceeds $L(0)$, it follows that there exists a time prior to $T_{1}$ when the returns to leading and following are identical. This time is denoted as $T_{0}$.

In each of the cases depicted in fig. 1, there is a period of time in which the firms have an incentive to preempt, but where preemption involves forgoing gains from declining adoption costs. Can the firms avoid the dissipation of rents from early adoption by tacitly agreeing to delay adoption until some time after $T_{0}$ ? In the absence of any uncertainty about firm type, FT have shown that the answer to this question depends upon when $L$ achieves a global maximum. In fig. 1a, it occurs before $\widehat{T}$, and in this case, rents are dissipated. The equilibrium outcome consists of one of the firms preempting at $T_{0}$ and the other firm adopting at $\hat{T}$. In fig. $1 \mathrm{~b}$, the global maximum occurs after $\widehat{T}$, and in this case, firms can avoid competing away the rents - joint adoption at time $T_{2}$ is an equilibrium outcome. ${ }^{3}$ This situation is likely to occur if the optimal response of the follower to adoption by the other firm does not involve a long delay.

The main point of this section is to show that innovator firms can tacitly agree to delay adoption in situations such as those depicted in fig. 1a if they have arbitrarily small doubts about the innovative capabilities of their rivals. The intuition behind this result is best given in a discretized version of the game. Suppose firms can only move at times $\Delta$ units apart and firm $i$ is supposed to adopt at $T_{0}$ whenever it is as an innovator. To ensure that firm $i$ has no incentive to wait at $T_{0}$, an innovator firm $j$ must threaten to adopt at $T_{0}+\Delta$. This strategy is clearly an optimal response for firm $j$ if it is certain that firm $i$ will adopt at $T_{0}$. However, it is not optimal if firm $j$ has some

\footnotetext{
${ }^{3}$ The model possesses multiple equilibria, a continuum of joint adoption equilibria and the preemption equilibrium. FT present several arguments for selecting joint adoption at $T_{2}$ as the "reasonable' equilibrium of the game.
} 
doubts about firm i's innovative capabilities. In that case, observing no adoption at $T_{0}$ would lead firm $j$ to conclude that firm $i$ is an imitator. Given this belief, its optimal response is to wait until $T_{1}$ to adopt. This in turn would give firm $i$ an incentive to behave like an imitator even when it is not. A similar argument rules out strategies in which innovator firms are certain to adopt beforc $T_{1}-\Delta$. Thus, in any equilibrium, the event in which innovator firms delay adoption until period $T_{1}-\Delta$ must occur with positive probability.

What then is the equilibrium? In the appendix, I show that the search for an equilibrium in the continuous time game can be restricted to the set of distribution functions in which both innovator firms wait until some time $\tau$ after $T_{0}$, and then randomize continuously until either one of the firms adopts or time $T_{1}$ is reached. To determine the equilibrium strategies, recall from the definition of a mixed strategy equilibrium that each player must be indifferent between any pair of pure strategies in the support of the mixture. In our context, this implies that $P^{i}\left(t, G^{j}\right)$ has to be constant on the interval $\left(\tau, T_{1}\right)$. Differentiating with respect to $t$ then yields

$$
0=(1-q)) g^{j}(t)[F(t)-L(t)]+\left[(1-q)\left(1-G^{j}(t)\right)+q\right] L^{\prime}(t) .
$$

Let $\mu^{j}(t)$ denote the hazard rate of an innovator firm $j$ at time $t$ (i.e., $\left.\mu^{j}(t) \equiv\left[d G^{j}(t) / d t\right] /\left[1-G^{j}(t)\right]\right)$, and let $q^{j}(t)$ denote firm $j$ 's reputation at time $t$. Applying Bayes rule,

$$
q^{j}(t)=q /\left[(1-q)\left(1-G^{j}(t)\right)+q\right] .
$$

Substituting (3.2) into (3.1) yields the differential equation for $G^{j}$ :

$$
L^{\prime}(t)=-\mu^{j}(t)\left[\left(1-q^{j}(t)\right)(F(t)-L(t))\right] .
$$

This equation states that, conditional on reaching time $t, \mu^{j}(t)$ must equate the instantaneous gain from delay to the expected marginal cost from waiting. The gain from waiting is measured by $L^{\prime}$, which is increasing, and the expected cost of waiting is given by the product of the value of the preemption losses, $(F(t)-L(t))$, and the instantaneous change in the probability of preemption, $\left(1-q^{j}(t)\right) \mu^{j}(t)$. Notice that the differential equation is well-behaved on any interval where returns from leading are different from the returns from following.

When firm $j$ randomizes according to a strategy such as the one defined by (3.3), its reputation, assuming it does not preempt, changes according to the differential equation

$$
\mathrm{d} q^{j} / \mathrm{d} t=\mu^{j}(t) q^{j}(t)\left(1-q^{j}(t)\right) .
$$


Eq. (3.4) is obtained from (3.2) by differentiation. Note that $q^{j}(t)$ is strictly increasing with time as long as $\mu^{j}(t)$ is positive. If firm $j$ adopts at time $t$, then firm $j$ is revealed as an innovator, and $q^{\mathrm{j}}(t)$ 'jumps' downward to 0 an instant later.

The pair of differential eqs in (3.3) and (3.4) determine the rates of change in firm $j$ 's reputation and probability of adoption. They can be solved to obtain firm $j$ 's equilibrium strategy as well as the time path for its reputation. Using (3.3) to substitute for $\mu^{j}(t)$ in eq. (3.4) yields

$$
\mathrm{d} q^{j}(t) / \mathrm{d} t=-q^{j}(t) L^{\prime}(t) /[F(t)-L(t)] .
$$

Integrating both sides of eq. (3.5) on an interval $(\tau, t)$,

$$
\log q^{j}(t)-\log q^{j}(\tau)=-\int_{\tau}^{t} L^{\prime}(s) /[F(s)-L(s)] \mathrm{d} s .
$$

Exponentiating both sides of (3.6), solving for $q^{j}(t)$, and imposing the boundary condition $q^{j}(\tau)=q$ then gives

$$
q^{j}(t)=q / I(\tau, t),
$$

where $I(\tau, t)=\exp \left\{\int_{\tau}^{t} L^{\prime}(s) /[F(s)-L(s)] \mathrm{d} s\right\}$. Finally, substituting (3.7) into (3.3), solving for $G^{j}(t)$, and imposing the boundary condition $G^{j}(\tau)=0$ yields

$$
G^{j}(t)=1-\exp \left\{\int_{t}^{t} L^{\prime}(s) /[(F(s)-L(s))(1-q / I(\tau, s))] \mathrm{d} s\right\} .
$$

What remains to be determined is the value of $\tau$. Equilibrium requires that each innovator firm adopts with probability 1 by time $T_{1}$. Consequently, if $T_{1}$ is reached and no firm has adopted, each firm is certain that the other firm is an imitator type. Imposing this condition on eq. (3.5) implies that $\tau$ must solve the equation $q=I\left(\tau, T_{1}\right)$. It is easily checked that $I\left(t, T_{1}\right)$ is monotone increasing in $t$ so, if a solution exists, it is unique. To establish existence, note first that $L^{\prime}(t)$ is bounded and $F^{\prime}(t)$ is positive. Using L'Hospital's rule, this implies that $L^{\prime}(t) /[L(t)-F(t)]>1 / t$ near $T_{0}$, which in turn implies that $\lim _{t \downarrow T_{0}} I\left(t, T_{1}\right)=0$. Since $\lim _{t \uparrow T_{1}} I\left(t, T_{1}\right)=1$, it follows that a solution exists.

Proposition 1. Suppose $T_{1}$ is a global maximum for $L$. Then a unique equilibrium exists in which for each $i=1,2, G^{i}$ satisfies eq. (3.8) on an interval $\left[\tau, T_{1}\right]$ where $G^{i}(\tau)=0$ and $\tau$ solves $q=I\left(\tau, T_{1}\right)$.

Proposition 1 states that, in situations where preemption gains are large and firms entertain doubts about the willingness of their rival to adopt first, there is a unique equilibrium in which each innovator firm does not adopt 
prior to some time $\tau$ between $T_{0}$ and $T_{1}$. After $\tau$, each innovator firm randomizes continuously until one of them adopts. Each is certain to adopt by $T_{1}$. Since adoption occurs after $T_{0}$, rents are positive for each firm. Ex ante returns are the same for each firm, but ex post returns are not equalized across firms, since the leader earns a higher payoff than the follower.

What are the factors affecting the degree of cooperation which can be sustained? To answer this question, suppose we approximate the returns to leading and following on $\left[T_{0}, T_{1}\right]$ by the linear functions $\widetilde{L}(t)=a t, \widetilde{F}(t)=b t$, where $a$ and $b$ are positive rates of increase, and $a$ exceeds $b$. Applying Proposition 1 yields,

$$
\tau=T q^{(a+b) / a},
$$

where $T$ is the length of time between $T_{1}$ and $T_{0}$. Thus, the fraction of time in which firms tacitly agree not to adopt increases with the probability of being an imitator, and decreases with the rate of change in preemption rents, $(a-b)$. Notice that the period of cooperation can be quite long even when $q$ is small. This is likely to occur when the rate of decline in adoption costs is relatively large, for this would imply a small value for $(a-b)$ and a large value for $T$.

Of some interest is the question of whether the FT equilibrium can be justified as the limit of a sequence of equilibria of incomplete information games. The answer is yes. As $q$ gets small, $\tau$ approaches $T_{0}$, and all of the probability mass of $G^{i}$ is concentrated in an arbitrarily small interval near $T_{\mathrm{u}}$. The limiting distribution over outcomes converges (weakly) to a distribution which places one-half of its mass on the event in which firm 1 adopts at $T_{0}$ and firm 2 adopts at $\hat{T}$, and one-half on the event in which the roles of the two firms are reversed. Notice, however, that the strategies converge to functions which are not right-continuous, since they are equal to zero at $t=0$ and 1 at $t>0$. Hence, the limit of the equilibrium distributions is not an equilibrium in the limit game. It is this nonexistence result in the space of distribution functions that forced FT to extend the strategy space of a player $i$ to include functions that represents the 'intensity' with which she moves at times 'just after' $G_{i}(t)$ jumps to one.

\section{Uncertain profitability}

The game-theoretic papers on the timing problem have all assumed that adoption is certain to be a success. But, as McCardle notes, 'the history of innovation is replete with headstones of failed inventions, etched with the names of (defunct) firms which attempted to employ them'. Indeed, this uncertainty is the primary focus of the learning models.

How does the possibility of failure effect competition over adoption times? 
To give some precision to the discussion, suppose the costs of adoption take the form

$$
c(t, \theta)=\theta+e^{-\alpha t}
$$

where $\theta$ is a Bernoulli random variable that takes on value $k$ with probability $p$ and 0 with probability $1-p$. The value of $\theta$ is public knowledge after the first adoption and $k$ is assumed to be larger than $\left[\pi_{1}(2)-\pi_{0}(1)\right] / \delta$. Thus, the optimal response of the follower if costs are high is never to adopt. Given this behavior by the follower, the functions $L, F$, and $M$ can then be defined as before. They represent the expected returns of an innovator firm to leading, following and tying.

What effect does a small, positive value of $p$ have on the configuration given in figs. $1 \mathrm{a}$ and $1 \mathrm{~b}$ ? The substantive changes occur after $\hat{T}$, where the possibility of failure means that the follower is not certain to adopt immediately after the leader. Hence, the expected return functions are not identical after $\hat{T}$. There are then two possibilities. Either $L$ lies below $F$ after $\hat{T}$ or it lies everywhere above $F^{4}$ It can be shown that a sufficient condition for the former case to hold is that $\pi_{1}(1)<\delta k$, and for the latter, $\pi_{1}(1)>\delta k+$ $\pi_{1}(2)$.

The case in which $F$ shifts up relative to $L$ corresponds to a situation in which technologies are either 'good' or 'bad'. A technology is 'good' if it is worth adopting irrespective of the adoption decisions of other firms. It is 'bad' when the fixed costs of adoption cannot be recovered even if the other firms does not adopt. This is the condition given above. It ensures that the first adopter takes a loss ex post whenever adoption costs turn out to be high, so following can be better than leading. The other case corresponds to a situation in which the first adopter makes positive profits net of adoption costs in the high cost state, and they exceed those earned by the follower. In this case, its always better to lead than follow.

How do these changes in the relationships between the expected return functions affect equilibrium behavior? If $T_{1}$ continues to be the global maximum of $L$ and $L\left(T_{1}\right)$ exceeds $F\left(T_{1}\right)$, no innovator has any incentive to wait beyond $T_{1}$ to adopt. Consequently, the substantive changes occur in a period that is reached only if both firms are imitators. But, in that case, the changes arc not relevant since adoption never occurs. Hence, if preemption gains are large then, for relatively small values of $p$, Proposition 1 continues to apply with $L$ and $F$ interpreted as expected return functions.

\footnotetext{
${ }^{4} M$ always lies below both $L$ and $F$. The reason is that, if adoption costs turn out to be high, the returns to both the leader and the follower are higher if only one of them adopts than if both adopt simultaneously. The follower earns more because it is able to avoid adopting a technology which, given adoption by the other firm, is unprofitable. The leader earns more because its profit flow is higher if the other firm does not adopt.
} 
The situation is different when $T_{2}$ is the global maximum of $L$, that is, when preemption gains are relatively small. Joint adoption at $T_{2}$ cannot be an equilibrium since, depending upon the type of technology, either a firm wants to preempt an instant before or it wants to wait an instant to determine whether the technology is worth adopting. The analysis of these cases proceeds in much the same manner as in the preceding section. It is not difficult to show that the equilibrium must once again be in mixed strategies, and that the distributions must satisfy eq. (3.8). Rather than repeat the derivations, I will simply describe the equilibrium for each case and its properties.

The equilibrium for technologies that are either 'good' or 'bad' involves delay until $T_{2}$. After $T_{2}$, innovators face a tradeoff: each prefers to follow rather than lead but, if it has to lead, it prefers to do so earlier rather than later. $^{5}$ To resolve this conflict, they randomize continuously according to (3.8). Here $L^{\prime}$ measures the cost, rather than the gain, from waiting, and $F(t)-L(t)$ measures the gain, rather than the loss, from going second. As time passes and no adoption occurs, each innovator's conviction that its rival is an imitator grows and, with it, the desire to adopt. Each adopts with probability one in finite time. Thus, as in the deterministic case, rents from delayed adoption are positive and successful technologies are adopted more or less simultaneously. But, in contrast to FT's result, the adoption time is not efficient. Firms delay too long as each tries to persuade its rival to adopt first so that it can benefit from the information externality.

The equilibrium for technologies where leading always yields higher expected returns than following prior to $T_{2}$, is essentially the same as that of Proposition 1. The only difference is that the reputation-building period occurs prior to $T_{2}$ rather than $T_{1}$, with $\tau$ determined by the equation $q=I\left(\tau, T_{2}\right){ }^{6}$ Not surprisingly, the incentive to preempt reasserts itself and some rents are dissipated through early adoption.

\section{Conclusion}

In thcir scminal papcr, Kreps et al. (1982) demonstrated how incomplete information and reputation effects can be used to generate cooperative outcomes in preemption games such as the finitely repeated Prisoner's Dilemma. I have used their approach to argue that preemptive adoption may not be as pervasive a phenomena as the literature on the timing of adoption suggests. It is not unreasonable to suppose that firms may have doubts about

\footnotetext{
${ }^{5}$ Games with this kind of payoff structure are commonly called Wars of Attrition.

${ }^{6}$ This is the solution if $L(\tau)$ exceeds $L\left(T_{1}\right)$. If this condition is not met, one can show that the reputation-building period consists of two disjoint intervals, $\left[\tau . T_{1}\right]$ and $\left[\tilde{T}, T_{2}\right]$, where $\tilde{T}$ denotes the time between $T_{1}$ and $T_{2}$ that returns from leading are equal to those earned at $T_{1}$. The value of $\tau$ is then determined by the equation $q=I\left(\tau, T_{1}\right)+I\left(\tilde{T}, T_{2}\right)$.
} 
each other's desire or ability to adopt first. If so, they can build on these doubts to avoid the debilitating effects of competition. This point receives empirical support from the work by McKelvey and Palfrey (1991).

It is also of relevance to the debate on the persistence of monopoly. Gilbert and Newberry (1982) have argued that the monopolist always preempts the entrant and adopts a new technology just before it becomes profitable for the entrant to do so. Reinganum (1984) has shown that this preemptive outcome depends critically on the monopolist knowing precisely when the entrant intends to adopt. If success in $R \& D$ is stochastic, then the entrant is more likely to adopt first because it earns more from adoption (i.e., most of its profit is a transfer from the monopolist). A similar situation arises if firms have doubts about each other's innovative capabilities. I have shown elsewhere [Hendricks (1987)] that the monopolist and entrant will behave as they do in Proposition 1: they delay adoption for a period of time before randomizing. Furthermore, as in Reinganum's model, the entrant is more likely to adopt first than the incumbent.

\section{Appendix}

In this appendix, I state and prove the lemma which establishes necessary conditions for an equilibrium. For notational convenience, time is normalized so that $T_{0}$ is equal to 0 . Define

$$
\tau=\sup \left\{t<T_{1} \mid \exists i, \exists t^{\prime}<t, G^{i}(t)-G^{i}\left(t^{\prime}\right)=0\right\}
$$

to be the end of the last interval prior to $T_{1}$ during which one of the firms adopts with probability 0 .

Lemma 1. $\left(G^{1}, G^{2}\right)$ is an equilibrium only if, for $i=1,2$ :

(i) $\mathrm{G}^{\mathrm{i}}(0)<1$ and $\mathrm{r}^{\mathrm{i}}(0) \cdot \mathrm{r}^{\mathrm{j}}(0)=0$,

(ii) $\mathrm{G}^{\mathrm{i}}$ is continuous on $\left(0, \mathrm{~T}_{1}\right)$, and $\tau>0$ implies $G^{\mathbf{1}}(t)=0$ for $0 \leqq t<\tau$.

(iii) $G^{i}\left(T_{1}\right)=1$ and $r^{i}\left(T_{1}\right) \cdot r^{j}\left(T_{1}\right)=0$.

Proof. (i) Suppose an innovator firm $i$ adopts with probability 1 at time 0. Then, since $F(0)>M(0)$, the optimal response of an innovator firm $j$ at time 0 is to wait. If firm $i$ fails to enter at time 0 , then firm $j$ concludes that firm $i$ is an imitator. Given this belief, the optimal strategy of an innovator firm $j$ is to delay adoption until time $T_{1}$. But then the payoff to an innovator firm $i$ from waiting at time 0 and adopting at some later date prior to $T_{1}$ is larger than its payoff from adopting at time 0 . Hence, it waits at time 0 , contradicting the original hypothesis.

The second part of condition (i) follows from right-continuity of $G^{i}$ and the fact that $M(0)<F(0)$. 
(ii) These properties are proved in Hendricks and Wilson (1986).

(iii) Note first that $G^{i}(t)=G^{i}\left(T_{2}\right)$ for all $t>T_{2}, i=1,2$, since $L$ is decreasing on this range and $L=F=M$. For any $t \in\left[\hat{T}, T_{2}\right)$,

$$
\begin{aligned}
& P^{i}\left(T_{2}, G^{j}\right)-P^{i}\left(t, G^{j}\right) \\
&=\left(1-q^{j}(0)\right)\left\{\int_{t}^{T_{2}}[F(s)-L(t)] \mathrm{d} G^{j}(s)+r^{j}\left(T_{2}\right)\left[M\left(T_{2}\right)-L(t)\right]\right. \\
&\left.\quad+\left(1-G^{j}\left(T_{2}\right)\right)\left[L\left(T_{2}\right)-L(t)\right]\right\}+q^{j}(0)\left[L\left(T_{2}\right)-L(t)\right] \\
& \geqq {\left[L\left(T_{2}\right)-L(t)\right] q^{j}(0) } \\
&>0
\end{aligned}
$$

Hence, $G^{i}(t)=G^{i}(\hat{T})$ for all $t \in\left[\hat{T}, T_{2}\right), i=1,2$.

On the interval $\left(T_{1}, \hat{T}\right), L$ is strictly decreasing and $L$ is greater than $F$ and $M$. Condition (ii) then implies that there is an $\varepsilon>0$ sufficiently small, such that, for any $u \in\left(T_{1}, \hat{T}\right)$

$$
\begin{aligned}
& P^{i}\left(t, G^{j}\right)-P^{i}\left(T_{1}-\varepsilon, G^{j}\right) \\
&=\left(1-q^{j}(0)\right)\left\{\int_{T_{1}}^{t}\left[F(s)-L\left(T_{1}-\varepsilon\right)\right] \mathrm{d} G^{j}(s)+r^{j}(t)\left[M(t)-L\left(T_{1}-\varepsilon\right)\right]\right. \\
&\left.\quad+\left(1-G^{j}(t)\right)\left[L(t)-L\left(T_{1}-\varepsilon\right)\right]\right\}+q^{j}(0)\left[L(t)-L\left(T_{1}-\varepsilon\right)\right] \\
& \leqq {\left[L(t)-L\left(T_{1}-\varepsilon\right)\right] q^{j}(0) } \\
&<0 .
\end{aligned}
$$

Thus, $G^{\mathrm{i}}(t)=G^{\mathrm{i}}\left(T_{1}\right)$ for all $t \in\left(T_{1}, \hat{T}\right), i=1,2$.

Putting these results together implies that $r^{i}\left(T_{2}\right)=1-G^{i}\left(T_{1}\right)$ for each $i=1,2$. But, for $\varepsilon>0$ sufficiently small,

$$
P^{i}\left(T_{1}-\varepsilon, G^{j}\right)-P^{i}\left(T_{2}, G^{j}\right) \geqq\left[L\left(T_{1}-\varepsilon\right)-L\left(T_{2}\right)\right] q^{j}(0)>0 .
$$

This implies $r^{i}\left(T_{2}\right)=0$. Q.E.D.

\section{References}

Balcer, Y. and S.A. Lippman, 1984, Technological expectations and adoption of improved technology, Journal of Economic Theory 34, 292-318. 
Benoit, J.P., 1985, Innovation and imitation in a duopoly, Review of Economic Studies LII, 99-106.

Bergin, J., 1988, Continuous time repeated games of complete information, Mimeo, Queen's University.

Eaton, Curtis B. and R.G. Lipsey, 1979, The theory of market preemption: The persistence of excess capacity and monopoly in growing spatial markets, Economica 149-158.

Fudenberg, D. and J. Tirole, 1985, Preemption and rent equalization in the adoption of new technology, Review of Economic Studies LII, 383-401.

Fudenberg, D. and D.M. Kreps, 1987, Reputation in the simultaneous play of multiple oppontns, Review of Economics Studies LIV, no. 4, 541-568.

Gilbert, R. and R. Harris, 1984, Competition and mergers with lumpy investments, Rand Journal of Economics 15, 197-212.

Gilbert, R. and D. Newberry, 1982, Preemptive patenting and the persistence of monopoly, American Economic Review 72, no. 3, 514-526.

Hendricks, K. and C. Wilson, 1989, The war of attrition in discrete time, Mimeo.

Hendricks, K., 1987, Reputations in the adoption of a new technology, Hoover Working paper E-87-51.

Hendricks, K. and C. Wilson, 1986, Equilibria in preemption games with complete information, in: M. Majumdar, ed., Equilibrium and dynamics: Essay in honor of David Gale (MacMillan, 1992).

Hendricks, K., A. Weiss, and C. Wilson, 1988, The war of attrition in continuous time with complete information, International Economic Review 29, no. 4, 663-680.

Jensen, R., 1982, Adoption and diffusion of an innovation of uncertain profitability, Journal of Economic Theory 27, 182-193.

Jensen, R., 1988, Information cost and innovation adoption policies, Management Science 34, 230-239.

Kreps, D.M., P. Milgrom, J. Roberts and R. Wilson, 1982, Rational cooperation in the finitely repeated prisoners' dilemma, Journal of Economic Theory 17, 245-252.

Kreps, D.M. and R. Wilson, 1982, Reputation and imperfect information, Journal of Economic Theory $17,253-279$.

McKelvey, R.D. and T.R. Palfrey, 1991, An experimental study of the centipede game, Mimeo, CalTech.

McCardle, K., 1985, Information acquisition and the adoption of new technology, Management Science 31, 1372-1389.

Reinganum, J., 1981a, On the diffusion of new technology: A game-theoretic approach, Review of Economic Studies 153, 395-406.

Reinganum, J., 1981b, Market structure and the diffusion of new technology, Bell Journal of Economics 12, no. 2, 617-624.

Reinganum, J., 1983, Technology adoption under imperfect information, Bell Journal of Economics 14, 57-69.

Reinganum, J., 1983, Uncertain innovation and the persistence of monopoly, American Economic Review 73, Sept., 741-747.

Simon, L. and M. Stinchcombe, 1986, Extensive form games in continuous time. Part I: Pure strategies, Mimeo.

Simon, L., 1987, Basic timing game, Mimeo. 